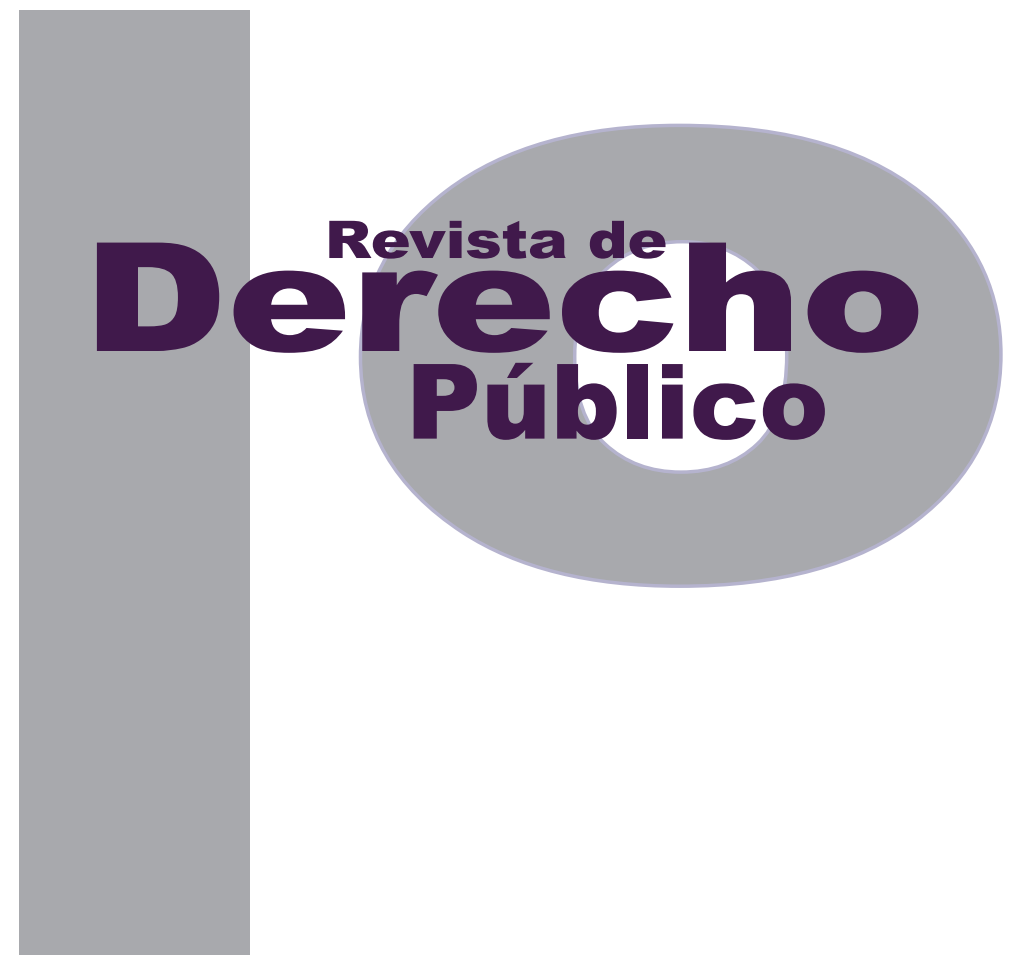

\title{
EL NEXO CAUSAL EN LA RESPONSABILIDAD MÉDICA DEL ESTADO SEGÚN LA JURISPRUDENCIA DEL CONSEJO DE ESTADO (1999-2011)
}

\author{
ERIC LEIVA RAMÍREZ
}

Universidad de los Andes

Facultad de Derecho

Revista de Derecho Público N. ${ }^{\circ} 30$

Enero - Junio de 2013. ISSN 1909-7778 


\title{
El nexo causal en la responsabilidad médica del Estado según la jurisprudencia del Consejo de Estado (1999-2011)
}

\author{
Eric Leiva Ramírez*
}

\section{RESUMEN}

La responsabilidad del Estado, por los daños antijurídicos que este ocasione por acción u omisión de sus funciones, se encuentra fundamentada en tres elementos: 1) un hecho, 2) el daño y 3) la relación de causalidad que debe existir entre los dos primeros. A su vez, la responsabilidad médica es uno de los aspectos que mayor trascendencia y cuestionamiento ha tenido en lo que se refiere a la imputación de daños al Estado. Precisamente, el nexo de causalidad es de los que más controversia genera, pues en ocasiones este se ha presumido o dado por probado sin que sea necesario que el demandante o demandado deba demostrar su existencia. Por ello, el presente documento busca exponer las teorías empleadas por la Sección Tercera del Consejo de Estado para imputar o absolver a la Administración Pública por los daños ocasionados en la prestación de servicios médicos, basados en la jurisprudencia del máxi-
State responsibility for damage that this causes wrongful act or omission of its functions, is based on three elements: 1) a fact, 2) damage and 3) the causal link must exist between the first two. In turn, medical liability is one of the most far-reaching and has been questioning in regard to the allocation of damages to the state. Indeed, one of the most controversial aspects generates is the causal link, because sometimes this has been presumed or taken for tested without requiring that the plaintiff or defendant must prove its existence.

Thus, this paper seeks to exhibit the theories used by the section three of the Consejo de Estado to charge or acquit public administration for damage in providing medical services, based on the jurisprudence of the Supreme Tribunal of the Contencioso administrativo of Colombia from 1999 to 2011. 
mo tribunal de lo contencioso administrativo de Colombia entre los años 1999 al 2011.

Palabras clave: Nexo causal, daño antijurídico, imputación, causalidad adecuada, causa probable, indicio, presunción de causalidad, imputación objetiva.
KeY WORDS: Causation, illegal damage, imputation, adequate causation, probable cause, evidence, presumption of causality, imputation objective. 
SUMARIO

Introducción - I. LA RELACIÓN DE CAUSALIDAD: ENTRE LA FALLA PRESUNTA, LA PÉRDIDA DE LA OPORTUNIDAD Y EL RETORNO A LA FALLA PROBADA - II. CAUSALIDAD VERSUS IMPUTACIÓN OBJETIVA: LA DISPUTA ENTRE LAS SUBSECCIONES DE LA SECCIÓN TERCERA DEL CONSEJO DE ESTADO - III. CONCLUSIONES - Bibliografía. 


\section{Introducción}

En materia de responsabilidad civil estatal es necesario, para imputar daños a la Administración ${ }^{1}$, la demostración de los siguientes elementos:

1) La existencia de un deber jurídico de actuar, es decir, la obligación constitucional, legal o reglamentaria a cargo de la entidad ${ }^{2}$ de ejercitar sus competencias y atribuciones en un plazo determinado por el ordenamiento jurídico o en un tiempo razonable y determinable cuando se satisface el supuesto de hecho de las normas que regulan la actividad del órgano, acción con la cual se habrían evitado los daños antijurídicos ocasionados; 2) el incumplimiento de esa obligación; 3) un daño antijurídico ${ }^{3}$, esto es, la lesión real y evaluable económicamente de un derecho o de un bien jurídico protegido al interesado o a un grupo de ellos que no están en el deber jurídico de soportar; y 4) la relación de causalidad entre la prestación anormal o deficiente del servicio y el daño ocasionado 4 (Ruíz, 2010, pp. 2 y 3).

Precisamente, sobre este último aspecto - la relación o nexo de causalidad- es donde se han

1 A lo largo de este documento debe entenderse Administración en su sentido más amplio, es decir, el desarrollo de la función administrativa independientemente de la rama del poder público que la desempeñe. Sobre el particular, véase Rodríguez (2008, pp. 15 a 22).

2 Entiéndase entidad bajo un criterio organicista, es decir, la persona física que actúa como miembro de la Administración y, por ende, sus actuaciones $u$ omisiones representan a la entidad a la cual se encuentra vinculada.

3 Sobre el concepto de daño antijurídico, véase Corte Constitucional (C-333 de 1996).

4 Los anteriores elementos son aplicables a todos los títulos de imputación de responsabilidad del Estado, incluyendo aquella que proviene de la prestación de servicios médicos. Sin embargo, es importante mencionar que existen juristas que tienen posturas diferentes en relación con estos elementos. Sobre el particular, véase Gil Botero (2011, pp. 21 a 39). presentado mayores controversias, tanto jurídicas como conceptuales en los diferentes campos de la ciencia del derecho, especialmente $-\mathrm{y}$ para el caso colombiano- en aquellos que son competencia de la jurisdicción de lo contencioso administrativo.

Por lo anterior, aquí se presenta el producto de una investigación que busca describir el proceso teórico que ha tenido que desarrollar el Consejo de Estado a través de su Sección Tercera, para justificar la necesidad de una relación de causalidad en los casos en que deba absolver o condenar a la Administración por la prestación de servicios médicos.

En efecto, a lo largo de estos últimos doce años, el Consejo de Estado ha pasado de una presunción de falla de la Administración -desarrollo jurisprudencial sostenido hasta el año 2000-, a hacer uso de la teoría de la carga dinámica de la prueba y posteriormente exigir del demandante la prueba del nexo causal, hasta llegar finalmente al uso de prueba indiciaria y la teoría de las probabilidades para demostrar o no la existencia de un nexo de causalidad. Esta dificultad empieza a ser superada gracias a la acogida que da la subsección $\mathrm{C}$ de la Sección Tercera del Consejo de Estado a la teoría de la imputación objetiva.

Ahora bien, la escogencia del año 1999 como punto de partida de la investigación se debe a que fue, a partir de ese momento, cuando se empezó a admitir la dificultad de prueba para el nexo causal, lo que trajo como consecuencia las teorías del grado suficiente de probabilidad (disminución del estándar de prueba), los alige- 
ramientos probatorios y la prueba indiciaria. En el mismo sentido, el año 2011 corresponde al final del periodo seleccionado para la primera etapa de esta investigación.

En el mismo sentido, el análisis de la evolución de una figura jurídica también es un trabajo histórico, de ahí que para la elaboración de este documento se haya recurrido a los fallos del Consejo de Estado como fuente primaria, con el fin de demostrar las dificultades $-\mathrm{y}$ no pocas contradicciones- en las cuales se ha visto inmersa la Sección Tercera para explicar la causalidad en materia médica, de lo que se podría llegar a inferir que el Consejo de Estado desconoce sus propios precedentes con tal de justificar la existencia de un nexo causal5; esto es lo que permitiría afirmar que el presente texto puede ser considerado un trabajo histórico.

Ahora bien ¿puede ser posible hacer un trabajo histórico con base en la aplicación de unas teorías jurídicas y los conceptos que las componen? La respuesta es sí. Para fundamentar esta afirmación se citan las palabras empleadas por Helmut Coing (1982, pp. 225 a 249):

La Historia del Derecho, en cuanto considera cada una de las normas jurídicas en su relación histórica, nos proporciona claridad sobre su significado originario. Pero con ello la interpretación y aplicación de una norma jurídica no ha terminado. La comprensión histórica de la norma jurídica, hay que confesarlo, es el punto de partida de toda interpretación honesta de la misma, pues incluso cuando a la vista de un determinado problema llego a la conclu-

5 Sobre una crítica al nexo de causalidad, véase Leiva (2009, pp. 161 a 174). sión de que no puedo aplicar una regulación existente en el Derecho positivo simplemente sin cambiarla, es decir, si yo estoy frente a una “laguna jurídica” que trato de suplir por analogía, restricción, etc., en ese caso yo sólo puedo trabajar limpiamente desde el punto de vista metodológico si sé primero cuál era el sentido originario de la norma en cuestión. Este parecer fue elaborado precisamente en Alemania por la jurisprudencia de intereses, dominante en la enseñanza del Derecho moderno y del actual. Si una norma jurídica regula conflictos de intereses, para poder comprenderla debe saber cuáles eran los conflictos que tuvo presente el legislador al formularla.

La consideración histórica no es, pues, toda la Dogmática jurídica. Pero sí es una parte importante de la misma.

Entre tanto, de esto no puede deducirse que el empleo de los conceptos jurídicos de la Dogmática por los historiadores del Derecho sea un método completamente equivocado. Y esto, porque en primer lugar hay conceptos de naturaleza muy general, que se refieren a estructuras que se encuentran en muchas formas de sociedad. Me refiero, por ejemplo, a la propiedad privada o a la diferencia entre contrato y delito. Incluso, se puede citar el concepto de equidad como contrapuesto al Derecho estricto. Tales conceptos nos pueden ayudar a ordenar provisionalmente y comprender las reglas de un ordenamiento jurídico del pasado.

Finalmente, un jurista formado en el Derecho moderno verá los textos históricos de ordenamientos pasados de una manera distinta a como los ve uno que no es jurista, por ejemplo un filólogo, porque el jurista conoce la problemática jurídica fundamental, a saber, encontrar ordenamientos y porque él comparte esta 
problemática general con los legisladores y jueces de épocas pasadas.

Por consiguiente, la Dogmática moderna es importante para el historiador del Derecho.

Según esto, la relación entre Historia del Derecho y Dogmática jurídica es compleja; se puede decir que ambas disciplinas están ensambladas una en la otra. Cada una de ellas es una ciencia autónoma, pero ninguna de ellas puede entenderse sin la otra.

Por lo anterior, el presente análisis puede ser considerado como un inusual trabajo de historia de la dogmática jurídica, en el que su objeto de estudio son las teorías sobre la relación de causalidad y la aplicación que de estas ha hecho la Sección Tercera del Consejo de Estado en materia de responsabilidad médica, desde el año de 1999 hasta el segundo semestre del año 2011.

Por lo tanto, se trata de hacer una descripción lo más objetiva posible de la jurisprudencia empleada. Sin embargo, ello no significa que no exista una visión crítica, cuando se demuestra la dificultad y -en no pocas ocasiones-, las incoherencias por parte de la Sección Tercera (cuando frente a hechos similares, se emiten pronunciamientos diferentes), para absolver o condenar a la nación por la demostración o no de una relación de causalidad.

Para la realización de este trabajo se hizo un estudio de noventa (90) sentencias, de las cuales se escogieron 17 aplicando como criterio su mayor grado de complejidad respecto al nexo de causalidad. Es más, en muchas de ellas resul- ta tan difícil probar la existencia causal, que la Sección Tercera del Consejo de Estado prefirió esquivar su estudio.

Resulta importante aclarar que el presente documento no pretende elaborar una línea jurisprudencial o el precedente elaborado por la Sección Tercera en materia de responsabilidad médica estatal. El que se haga una relación de providencias judiciales no significa que sea el objetivo de esta investigación. Por el contrario, la descripción cronológica de algunos fallos judiciales busca demostrar cómo esta Sección del Consejo de Estado ha venido cambiando de criterios jurisprudenciales en la medida que se le dificulte demostrar la existencia de una relación causal. Adicionalmente, resultaría bastante difícil elaborar una línea jurisprudencial con las providencias judiciales de un Tribunal que aplica diferentes criterios a unos mismos hechos ${ }^{6}$. El objetivo de este trabajo es demostrar las dificultades e incoherencias que ha tenido el Consejo de Estado -Sección Tercera- para aplicar las teorías que tratan de fundamentar la existencia del nexo de causalidad en la responsabilidad por falla médica del Estado.

El desarrollo del texto será de la siguiente manera: 1) citación de los fallos de la Sección Tercera del Consejo de Estado desde 1999 hasta el segundo trimestre del año 2010, fecha en la cual entraron en funcionamiento las subsecciones $A$, B y C de la Sección Tercera del Consejo de Estado creadas por el artículo 10 de la Ley 1285 de 2009 y, 2) los fallos del Consejo de Estado

6 Sobre los elementos y características que debe tener una línea jurisprudencial y el precedente judicial, véase López (2006, pp. 139 a 192). 
pronunciados desde el anterior periodo hasta finales del segundo semestre del año 2011.

\section{LA RELACIÓN DE CAUSALIDAD: ENTRE LA FALLA PRESUNTA, LA PÉRDIDA DE LA OPORTUNIDAD Y EL RETORNO A LA FALLA PROBADA}

El primer viso de cambio de tendencia jurisprudencial fue la acogida de la teoría de la pérdida de la oportunidad, la cual permite hacer caso omiso de la prueba de la relación de causalidad (aunque no de su estudio). En efecto, el Consejo de Estado toma la decisión audaz e injusta para con la entidad demandada, de condenarla por la totalidad del daño sufrido por la parte demandante, pese a que sin duda alguna, admite que no existe prueba del nexo de causalidad, sino la simple pérdida de la oportunidad (Consejo de Estado, 1999) ${ }^{7}$ :

\section{$[\ldots]$}

Si bien es cierto que no existe certeza en cuanto a que de haberse realizado un tratamiento oportuno el paciente no hubiera muerto pues nunca se tuvo un diagnóstico definitivo de la enfermedad que padecía, sí lo es en cuanto a que el retardo de la entidad le restó oportunidades de sobrevivir. Se trata en este caso de lo que la doctrina ha considerado como una "pérdida de oportunidad".

Posteriormente, el mismo órgano, para decidir condenar a la entidad demandada, acude a dos figuras excluyentes entre sí: por un lado, se da

7 Expediente 10755. Para facilitar la búsqueda de la cita, se pondrá en nota al pie el número de radicación del proceso fallado. por probado el nexo causal a partir de la alta probabilidad de que la intervención quirúrgica hubiese sido la causa del daño en el paciente; sin embargo, en otro aparte dice que no está probado que sin esa culpa de la demandada el daño no se habría producido y que en tales circunstancias, de todas maneras se había privado a la víctima de la oportunidad de haber evitado el daño:

\section{$[\ldots]$}

En conclusión, no existe certeza en el sentido de que la paraplejia sufrida por Marianella Sierra Jiménez haya tenido por causa la práctica de la biopsia. No obstante, debe tenerse en cuenta que aunque la menor presentaba problemas sensitivos en sus extremidades inferiores antes de ingresar al Instituto Nacional de Cancerología, se movilizaba por sí misma y que después de dicha intervención no volvió a caminar. Esto significa que existe una alta probabilidad de que la causa de la invalidez de la menor sea la falla de la entidad demandada. Probabilidad que además fue reconocida por los médicos de la entidad demandada.

En consideración al grado de dificultad que representa para el actor la prueba de la relación de causalidad entre la acción del agente y el daño en los casos en que esté comprometida la responsabilidad profesional, no sólo por la complejidad de los conocimientos científicos y tecnológicos en ella involucrados sino también por la carencia de los materiales y documentos que prueben dicha relación causal, se afirma que cuando sea imposible esperar certeza o exactitud en esta materia "el juez puede contentarse con la probabilidad de su existencia", es decir, que la relación de causalidad queda probada "cuando los elementos de juicio sumi- 
nistrados conducen a "un grado suficiente de probabilidad'".

Ahora bien, es cierto que no existe certeza en cuanto a que de no haberse producido la práctica de la biopsia la menor no hubiera quedado inválida, pero sí es cierto que la intervención le restó la oportunidad de aliviar o al menos mejorar su situación física sin padecer el estado de invalidez que sufre y por esta razón la entidad demandada deberá indemnizar al actor los daños sufridos con ocasión de la paraplejia de su hija, derivada de la falla médica.

La contradicción es evidente, porque una cosa es dar por cierto el nexo causal a partir de una probabilidad preponderante, y otra afirmar que el nexo causal no está probado, pero que en virtud de la teoría de la pérdida de la oportunidad, la víctima tiene derecho a una indemnización. A ciencia cierta, no queda claro si la condena se fundamenta en que se probó el nexo causal o en que a la afectada se le privó de la oportunidad de haber evitado el daño. Dicha concepción se repite en un fallo posterior (Consejo de Estado, 2000):

$[\ldots]$

En otras palabras, si bien no puede considerarse probada la relación de causalidad entre la actitud omisiva de la entidad demandada y la muerte del paciente, sí está claramente acreditada aquélla que existe entre dicha actitud y la frustración de su chance de sobrevida. Esta distinción es fundamental para enervar cualquier observación relativa a la laxitud en la prueba de la causalidad. Ésta se encuentra totalmente acreditada respecto de un daño cierto y actual, que no es la muerte, sino la disminución de probabilidades de sanar.

En ese mismo año, el Consejo de Estado niega la responsabilidad del demandado básicamente porque el demandante no probó el nexo causal, prueba que según la sentencia siempre le corresponde a este (divergiendo de lo dicho en los fallos mencionados), a pesar de que las circunstancias probatorias eran semejantes a las relacionadas en fallos previos y lo lógico sería que se aplicara la misma resolución; no obstante, ello no ocurre así, pues la inferencia de la existencia o no de un nexo de causalidad para este caso en particular, se realiza por la aplicación de indicios, para ir dejando a un lado el concepto de "carga dinámica de la prueba" (Consejo de Estado, 2000) ${ }^{9}$. Sin embargo, el uso de la prueba indiciaria implica la aplicación de las reglas de la sana crítica, las cuales a su vez conllevan cierta subjetividad, más aún cuando es el máximo tribunal de lo contencioso administrativo quien las define. En este caso, se habla de probabilidad de la existencia del nexo causal, mas no de certeza (Consejo de Estado, 2000)10:

\section{$[\ldots]$}

Se observa, conforme a lo anterior, que, tratándose de la relación de causalidad, no se plantea la inversión -ni siquiera eventual- del deber probatorio, que sigue estando, en todos los casos, en cabeza del demandante. No se encuentra razón suficiente para aplicar, en tales situaciones, el citado principio de las cargas probatorias dinámicas. Se acepta, sin em-

9 Radicación número: 12548.

10 Radicación número 11901. 
bargo, que la demostración de la causalidad se realice de manera indiciaria, siempre que, dadas las circunstancias del caso, resulte muy difícil -si no imposible- para el demandante, la prueba directa de los hechos que permiten estructurar ese elemento de la obligación de indemnizar.

En la valoración de estos indicios tendrá especial relevancia el examen de la conducta de las partes, especialmente de la parte demandada, sin que pueda exigírsele, sin embargo, que demuestre, en todos los casos, cuál fue la causa del daño, para establecer que la misma es ajena a su intervención. En efecto, dadas las limitaciones de la ciencia médica, debe aceptarse que, en muchas ocasiones, la causa de la muerte o el empeoramiento del paciente permanece oculta, aun para los propios médicos.

$[\ldots]$

Por último -y no obstante que el análisis sobre la existencia de una fuerza mayor, o de un hecho de la víctima o de un tercero sólo es pertinente cuando se ha demostrado que la entidad demandada causó el daño, a fin de establecer si el nexo inicialmente establecido resulta apenas aparente-, la Sala considera necesario advertir que, en el caso planteado, está probada la intervención de causas extrañas en la producción del perjuicio cuya indemnización se reclama en el proceso.

$[\ldots]$

Se concluye, entonces, que la práctica tardía de la cirugía filtrante, cuyo objetivo era tratar el glaucoma que presentaba el paciente, tuvo importante injerencia en la producción del daño definitivo sufrido por éste. Y si bien no puede establecerse con certeza que la tardanza sea im- putable a la víctima, o al hecho de terceras personas, es claro que en ello no tuvo participación alguna la entidad demandada.

$[\ldots]$

Con fundamento en todo lo anterior, se tiene que no está demostrada la responsabilidad de la entidad demandada, situación que impide el análisis de la posible responsabilidad del médico llamado en garantía. Se confirmará, en consecuencia, el fallo apelado. (Negrillas fuera del texto original).

En esta providencia resultó más importante demostrar la no certeza del nexo de causalidad que el daño ocasionado. En efecto, el Consejo de Estado establece la existencia de un perjuicio (obsérvese texto en negrillas), pero a su criterio no se probó la relación de causalidad, a pesar de que el mismo órgano establece en este fallo que no es necesaria la prueba plena del nexo causal por parte del demandado.

A pesar de lo anterior, en un fallo posterior, el Consejo de Estado no obró de la misma forma. A pesar de que el demandante no probó el nexo causal, terminó condenando a la nación, haciendo uso de la teoría de la pérdida de la oportunidad. Sin embargo, un día después, la misma Sección Tercera emite una providencia en la cual afirma que el nexo de causalidad nunca se presume, pero que cuando aparece que la falla del servicio es una causa probable, el juez debe darlo por probado. Al respecto, dicho fallo establece (Consejo de Estado, 2002) ${ }^{11}$ :

11 Radicado número 11605. 
do la existencia de condiciones particulares en

Se ha considerado necesario presentar previamente estas reflexiones (sic) serán tenidas en cuenta para valorar la prueba obrante en el proceso a fin de establecer si está demostrada, en este caso, la responsabilidad de la entidad demandada. Sólo resta advertir como también lo hizo la Sala en el fallo que acaba de citarse que, el análisis de la causalidad debe proceder siempre al de la existencia de la falla del servicio, en los casos en que ésta se requiere para estructurar la responsabilidad de la entidad demandada. En efecto, sólo aquellas fallas a las que pueda atribuirse la producción del daño tendrán relevancia para la demostración de dicha responsabilidad, de manera que la inversión del orden en el estudio de los elementos citados puede dar lugar a que la falla inicialmente probada resulta inocua, 0 a valorar indebidamente los resultados del examen de la conducta, teniendo por demostrado que no lo está.

$[\ldots]$

No puede descartarse, entonces, que una de estas circunstancias se hubiera presentado en el caso de la demandante, sobre todo si se tiene en cuenta que los otros factores asociados al riesgo de esa complicación se refieren a condiciones particulares del paciente, cuya existencia, en el caso de la demandante, no ha sido demostrada.

En estas condiciones, se concluye que existen elementos suficientes para considerar probado que el daño sufrido por la señora Jaimes de Mendoza puede ser imputado a una falla del ISS, en la prestación del servicio médico asistencial a su cargo.

Adicionalmente, conforme a la doctrina citada, puede agregarse que, por no haberse demostra- la paciente que la expusieran de manera especial a dicho riesgo, es probable que su realización estuviera asociada a la impericia del anestesista o a la utilización de una aguja muy larga, por no conocerse suficientemente la biometría del globo ocular, aspecto cuya relevancia reconoce uno de los médicos declarantes.

Por lo demás, si las conclusiones anteriores no pudieran considerarse suficientes, no le cabe duda a la Sala de que el caso concreto es uno de aquéllos en los que la demostración de los hechos que estructuran la falla, salvo en cuanto se refiere a la aplicación de la anestesia no indicada, resulta prácticamente imposible para la víctima, dado que se trata de acreditar la impericia en la práctica de un procedimiento que no fue realizado en presencia de otros profesionales distintos al directamente encargado del mismo, y sobre el cual no fue posible obtener mayor información en virtud de la falta de voluntad de la entidad demandada para aportar al proceso las pruebas respectivas. Sería procedente, en estas condiciones, con fundamento en la equidad, como criterio auxiliar de la actividad judicial, acudir, de manera excepcional, a la inversión del deber probatorio de dicho elemento de la responsabilidad, inaplicando el artículo 177 del C. de P. C., conforme a lo explicado en la primera parte de estas consideraciones, y presumir, entonces, que la administración de la anestesia local a la señora Jaimes de Mendoza se hizo con negligencia e impericia, por parte del anestesiólogo del ISS que tuvo a su cargo el procedimiento. (Negrillas fuera del texto).

En fallo posterior (Consejo de Estado, 2005) ${ }^{12}$, la Sección Tercera condenó a la entidad de-

12 Radicación número: 14699 
mandada por no haber hecho todo lo necesario para que la víctima tuviese una debida y oportuna atención médica. Si bien es cierto, no está claramente demostrado que esta haya sido la causa del deceso (pudo haber sido los golpes recibidos en la penitenciaría o una enfermedad que poseía con anterioridad al momento de ser recluido), considera la Corporación, que al no haber remitido al recluso a un centro médico de forma ágil, provocó que se presentara el proceso infeccioso que ocasionó la muerte. Al igual que en el fallo inmediatamente anterior, el Consejo de Estado deduce que la causa eficiente radica en la negligencia de la entidad demandada, y no en la relación que debe existir entre el hecho generador o falla y el daño. Sin embargo, para este caso existe un elemento adicional, consistente en que no solo fue necesario probar la falta, sino que se presume la culpa, pues fue suficiente para declarar la responsabilidad administrativa, el hecho de que el occiso falleció una vez fue remitido desde el centro penitenciario a la clínica:

$[\ldots]$

La doctrina ha señalado que la causa eficiente es lo que se considera como fundamento $u$ origen de algo; basta la verificación de la relación antecedente-consecuente para que pueda sostenerse que un hecho es productor y otro el producido, uno el engendrante y otro el engendrado. No interesa en la consideración meramente física si el encadenamiento es próximo o remoto, cercano o alejado en el tiempo o en el espacio: basta que ocurra, que exista, que se dé. "Cualquier suceso natural o hecho humano es susceptible de generar repercusiones que se expanden por todo el ámbito social al entrelazarse con otros hechos 0 acontecimientos que son, a su vez, consecuencia de sucesos anteriores. Esta expansión en el espacio y en el tiempo ocurre en círculos concéntricos, parecidos a los que produce una piedra al caer en el agua tranquila de un estanque; cuanto más alejados están del lugar del impacto, más débiles o imperceptibles se tornan por lo regular tales efectos". (Negrillas fuera del texto).

A pesar de lo anterior, el Consejo de Estado expone una tesis que contradice su propia doctrina, al establecer que no es aceptable presumir la relación de causalidad cuando de responsabilidad médica se trata. En efecto, al igual que en la sentencia anterior, los demandantes se limitaron a demostrar una indebida atención por parte de la entidad demandada y la tardanza por parte de esta en el envío del recluso a un centro médico especializado. La Corporación no condena a la Administración a pesar de que se demostró que la afectación se debió a una consecuencia de la patología adquirida con anterioridad a la valoración de capacidad laboral, pues el Consejo de Estado consideró que esta relación no fue probada por los demandantes. Al respecto, la providencia judicial en cuestión sostiene (Consejo de Estado, 2008) ${ }^{13}$ :

$[\ldots]$

"En enfermedades autoinmunes, el sistema inmunológico, que normalmente protege el cuerpo contra organismos extraños, ataca por error a los propios tejidos del cuerpo causando inflamación y, en algunos casos, daños a la mielina de la médula espinal".

13 Radicación número: 16646 
No obstante lo anterior, la Sala echa de menos la relación de causalidad entre este daño, sufrido por los demandantes a raíz del estado de salud del joven URIEL DAVID CARRASCAL LIZCANO y la actividad de la entidad demandada, puesto que no se acreditó en parte alguna que el estado de incapacidad actual del paciente así como las secuelas que sufre en su salud, hayan sido ocasionados por alguna acción u omisión de las autoridades médicas y sanitarias que lo atendieron, puesto que no basta con acreditar que hubo un contacto físico, entre el servicio médico y el paciente, para poder deducir la existencia de ese nexo causal necesario para poderle imputar responsabilidad a la entidad demandada, como tampoco resulta suficiente la afirmación de que la remisión del paciente al Hospital Militar Central fue tardía e inoportuna, convirtiéndose en la causa del daño.

Si bien en materia de responsabilidad médica de las entidades estatales la jurisprudencia de la Sala ha llegado a admitir la posibilidad de presumir la falla del servicio, en vista de la dificultad probatoria que en algunos eventos puede surgir para la parte actora respecto de circunstancias que escapan a su control en los tratamientos médicos, quirúrgicos y asistenciales, lo que sí no se ha admitido en ningún momento, es la presunción de este otro elemento, consistente en la acreditación de la relación causal entre el servicio y el daño sufrido.

Finalmente, quiere advertir la Sala que, si bien los documentos aportados por la apelante con su recurso no pueden ser legalmente valorados por cuanto su aportación fue inoportuna, el contenido de los mismos tampoco habría llevado a la Sala a tomar una decisión diferente, puesto que, contrario a lo afirmado por la parte actora, no se encuentra allí una prueba plena e irrefutable de la responsabili- dad que le atribuye a la parte demandada, en la medida en que se trata de oficios del Ejército Nacional, en los que se le informa que no se ha encontrado ninguna historia clínica del cadete URIEL DAVID CARRASCAL LIZCANO, relacionada con su atención durante los días 10 a 19 de julio de 1994 en el Dispensario de la Escuela de Cadetes, y a cambio se le entrega la relación de los pacientes que estuvieron hospitalizados en el mismo, dentro de los cuales se halla el demandante; pero observa la Sala, que el hecho de su atención y permanencia en el referido dispensario, no fue negado por la parte demandada, ni constituye prueba de una falla del servicio o de un nexo causal entre éste y el daño sufrido por los demandantes, de modo que absolutamente en nada cambiaría el sentido de la presente decisión, la valoración de dicho material documental.

En las condiciones anotadas, imposible resulta deducir la responsabilidad patrimonial de la entidad demandada, razón por la cual, la sentencia de primera instancia será confirmada. (Negrillas fuera del texto).

En este caso, no solo absuelve a la entidad demandada, sino que culpa a la víctima de su fatídico desenlace, pues no atendió a la sugerencia de su pariente de regresar al centro médico que un día antes le negó atención y lo obligó a dirigirse a un médico particular que por falta de exámenes, se negó a emitir un diagnóstico. No deja de ser paradójico cómo en otros fallos donde no se prueba el nexo causal, se condena a la Administración por no prestación del servicio, mientras que para este caso, la atención al usuario no solo es causal insuficiente para declarar responsable al Estado, sino que es culpa de la víctima por no haber regresado de nuevo 
al centro médico a buscar ser atendido. Al respecto, afirma el Consejo de Estado (2009): ${ }^{14}$

$[\cdots]$

Sin embargo, la certeza acerca de que el enfermo sí se presentó en CAJANAL en las primeras horas del 28 de septiembre de 1993, pero no fue atendido por el personal médico no resulta suficiente para establecer que la alegada falta de atención hubiere provocado el desenlace fatal, porque el material probatorio referido sólo indica en este caso los siguientes supuestos fácticos: i) que el paciente habría sido valorado por un médico particular, quien después de revisarlo habría establecido que el enfermo sí estaba en condiciones de esperar hasta el día siguiente para practicarse los exámenes médicos que arrojarían el diagnóstico de su estado de salud; ii) que habría estado en capacidad de tomar un bus y de regresar solo a su residencia; iii) que cuando él se sintió mal en su casa le habría indicado a su nuera que no era necesario trasladarse a un centro de salud porque él prefería esperar a que una de sus hijas le pusiera unos paños de agua caliente y le diera algo de tomar y iv) que a pesar de que el enfermo habría sufrido mareos y desmayos entre las 8:00 y 10:00 A.M., este sólo se habría trasladado al Hospital más cercano a las 12:30 P.M., todo lo cual aleja aún más algún criterio de responsabilidad que se pretenda imputar a la demandada.

$[\ldots]$

Todo lo anterior, no sólo no vincula a la entidad demandada sino que resalta que hubo falta de acción oportuna por parte de la víctima y de las personas que lo acompañaban, de forma tal que no se advierten los elementos necesarios para

Radicación número: 17425. declarar la responsabilidad de la demandada por la muerte del señor Tomás María Usuga.

En este orden de ideas y ante la falta de prueba acerca de la participación de la demandada en la ocurrencia del hecho dañoso, se impone confirmar la sentencia de primera instancia en cuanto negó las súplicas de la demanda.

\section{CAUSALIDAD VERSUS IMPUTACIÓN OBJETIVA: LA DISPUTA ENTRE LAS SUBSECCIONES DE LA SECCIÓN TER- CERA DEL CONSEJO DE ESTADO}

Las disposiciones y conceptos jurisprudenciales se mantenían "intangibles" en la medida que era un devenir de tendencias jurídicas que iban desde el regreso a la falla probada, la carga dinámica de la prueba y la restauración, como parámetro probatorio, de la necesidad de demostrar la existencia del vínculo causal, hasta la defensa de la concepción del indicio como solución para superar las dificultades que implicaría el retorno a las mencionadas teorías sobre la responsabilidad. Sin embargo, con el ingreso al Consejo de Estado del magistrado Enrique Gil Botero, se empezaron a dar los primeros visos de cambio a estas posturas jurisprudenciales. En efecto, mediante una aclaración de voto presentada en un fallo del año $2007^{15}$, el consejero Gil Botero expresa su "inconformidad" en cuanto a que los demás consejeros decidieron aprobar su ponencia siempre y cuando él suprimiese parte de esta. La supresión se realizó sobre la argumentación que exponía la diferencia entre causalidad e imputación, siendo esta última la

15 Radicación número: 16010. 
realmente importante pues no solo es una exigencia expresada en el artículo 90 de la Constitución Política, sino que al mismo tiempo es un concepto realmente jurídico a diferencia de la relación de causalidad. Resulta importante traer a colación dicha aclaración de voto ${ }^{16}$ :

\section{Argumentos sobre los cuales recae la presen- te aclaración de voto}

En la providencia ya señalada, la Corporación confirmó la decisión impugnada, en el sentido de denegar las pretensiones de la demanda y, en cuanto concierne a los elementos estructurales de la responsabilidad extracontractual del Estado, se optó por suprimir un acápite completo dentro del texto de la sentencia en donde se explicaba in extenso, la circunstancia por la cual un análisis estricto y riguroso del artículo 90 de la Constitución Política arriba a concluir que son sólo dos los elementos que estructuran la noción jurídica de responsabilidad extracontractual del Estado.

\section{$[\ldots]$}

2.1. La Sala, como se puntualizó anteriormente, parte del reconocimiento de que son varios los elementos estructurales de la responsabilidad extracontractual del Estado, los cuales serían, a saber: i) daño antijurídico, ii) nexo causal, iii) imputación y, en ocasiones, iv) hecho dañoso.

2.2. La anterior estructura conceptual, en mi criterio, desconoce los postulados sobre los cuales se fundamenta la responsabilidad del Estado a partir de la Carta Política de 1991,

16 Las cursivas y negrillas expuestas en el texto hacen parte de la providencia judicial original. Las notas al pie empleadas en la sentencia fueron suprimidas para reducir la extensión de la cita. en tanto el artículo 90 del estatuto superior estableció sólo dos elementos de la responsabilidad, los cuales son: i) El daño antijurídico y, ii) la imputación del mismo a una autoridad en sentido lato o genérico.

$[\ldots]$

“(...)" (negrillas fuera del texto original).

$[\ldots]$

2.3. Previo a cualquier análisis, es menester reseñar elementos estructurales de conocimiento jurídico que son inherentes a la problemática planteada, como quiera que de la posición que se asuma respecto a los mismos deriva la comprensión frente al tema objeto de estudio; es así, como bien vale la pena reseñar que son dos categorías diferentes la causalidad y la imputación, toda vez que el objeto de las ciencias naturales, es la naturaleza, mientras que el objeto de la ciencia del derecho, es el derecho; verdad que parece de perogrullo, pero de la cual se derivan consecuencias importantes que por obvias se dejan equivocadamente de lado, de allí que estamos en presencia de un dualismo entre la naturaleza como orden causal y la sociedad como orden normativo; y en ese entendimiento, los principios específicos que los rigen son el de la causalidad y el de la imputación que se expresan bajo leyes propias, y que aunque bien, se traducen bajo la forma de juicios hipotéticos que establecen una relación entre una condición y una consecuencia, en palabras de Kelsen, en uno y otro caso, se rigen por los principios de la necesidad (del ser) y el de la libertad (del deber ser). Podría decirse, igualmente, que dentro de las ciencias de la naturaleza la causalidad correspondería, tanto en su acepción primitiva como en la más refinada a que hubo lugar en el pensamiento 
aristotélico, a una forma de conocimiento en cuanto busca una explicación de los fenómenos, y por el contrario, las ciencias sociales a través de la imputación refiere la vinculación de conductas frente a actos o hechos bajo la conexión del deber, y no bajo el imperativo del tener, propio de la causalidad.

Así las cosas, según la disposición lógico-normativa del artículo 90 de la Constitución Política, se tiene que establecida la presencia del daño, algo lo tuvo que originar como realidad, toda vez que no es un efecto incausado. $Y$ en él se encuentra inmersa la causalidad, como parte o condición del efecto - DAÑO-.

\section{$[\ldots]$}

El segundo elemento que configura la responsabilidad patrimonial del Estado a la luz el artículo 90 constitucional es la imputabilidad del daño antijurídico a las autoridades públicas, aspecto en el cual también ha sido abordado por la jurisprudencia de esta Corporación y tratado profusamente por el Consejo de Estado. Esta última autoridad judicial ha sostenido que la imputación está ligada pero no se confunde con la causación material, por cuanto en ciertos eventos se produce una disociación entre tales conceptos, razón por la cual para imponer al Estado la obligación de reparar un daño "es menester, que además de constatar la antijuricidad del mismo, el juzgador elabore un juicio de imputabilidad que le permita encontrar un 'título jurídico' distinto de la simple causalidad material que legitime la decisión; vale decir, la 'imputatio juris' además de la imputatio facti. (Negrilla fuera del texto)

\section{$[\ldots]$}

La noción de daño antijurídico es invariable cualquiera sea la clase (contractual o extracon- tractual) o el régimen de responsabilidad de que se trate; consistirá siempre en la lesión patrimonial o extrapatrimonial que la víctima no está en el deber jurídico de soportar. (Negrillas y subrayado fuera del texto original).

Esta última cita es pertinente para recalcar en la cuestión objeto de estudio en la presente decisión, pues tal como lo ha entendido el Consejo de Estado, la disposición constitucional que regula la materia establece la obligación de reparar los daños antijurídicos provenientes de cualquier autoridad pública. En efecto, como se ha reiterado el precepto simplemente establece dos requisitos para que opere la responsabilidad patrimonial estatal, a saber, que haya un daño antijurídico y que éste sea imputable a una acción u omisión de una autoridad pública, sin hacer distingos en cuanto al causante del daño.

\section{$[\ldots]$}

Ahora bien, en materia del llamado nexo causal, debe precisarse una vez más que este constituye un concepto estrictamente naturalístico que sirve de soporte o elemento necesario a la configuración del daño, otra cosa diferente es que cualquier tipo de análisis de imputación, supone, prima facie, un estudio en términos de atribuibilidad material (imputatio facti u objetiva), a partir del cual se determina el origen de un específico resultado que se adjudica a un obrar -acción u omisión-, que podría interpretarse como causalidad material, pero que no lo es jurídicamente hablando porque pertenece al concepto o posibilidad de referir un acto a la conducta humana, que es lo que se conoce como imputación.

\section{$[\ldots]$}

Esa relación en el derecho, tradicionalmente llamada causalidad física, no puede seguir 
siendo la base del sistema, ni elemento autónomo, ya que es parte estructural del daño al posibilitar su existencia en la alteración o conformación mejor de una realidad, cosa diferente es la posibilidad de atribuir ese daño al obrar o no del sujeto, lo que constituye la imputación en sentido jurídico; más aún hoy día en que se habla de la crisis del dogma causal en las ciencias de la naturaleza, lo que ha permitido la conceptualización y desarrollo de criterios como el de la imputación objetiva y el deber de cuidado en el campo jurídico, desde luego.

En síntesis, mientras se mantenga la convicción de que la causalidad en su natural sentido óntico, hace parte de las ciencias sociales, y que constituye en ese entorno un elemento de la responsabilidad patrimonial, se incurre en un error al mezclar dos líneas paralelas, que corresponden a objetos de conocimiento diferentes: la naturaleza y el derecho, como ya se dijo. Y de otro lado, aunque el daño es producido por la acción u omisión, esto es, se da una relación entre dos hechos, eso hace parte de una regla de derecho -imputación- mas no causalidad, la imputación vincula conductas, por ello se ha dicho: "La ciencia del derecho no pretende, pues, dar una explicación causal de las conductas humanas a las cuales se aplican las normas jurídicas", o bien, en otro horizonte: "La diferencia entre la causalidad y la imputación se pone de manifiesto en la relación entre la condición y la consecuencia: en la ley de la naturaleza se designa a la condición como causa y a la consecuencia como efecto, pero no interviene ningún acto humano o sobrehumano. En la ley moral, religiosa o jurídica la relación entre condición y consecuencia se establece por actos humanos o sobrehumanos" ${ }^{17}$.

17 Otras aclaraciones de voto en el mismo sentido: Consejo de Estado (2007 y 2008), radicados número: 15382 y 27268 .
La no aceptación plena ${ }^{18}$ de los criterios expuestos por el consejero Gil Botero empezaron a variar con la entrada en vigencia de la Ley 1285 de 2009 que modificó parcialmente a la ley estatutaria de administración de justicia (Ley 270 de 1996); la norma en comento en su artículo 10 establece la creación de tres subsecciones en la Sección Tercera del Consejo de Estado. La mayoría de los nuevos consejeros iniciaron sus labores a partir del cuarto trimestre el año 2010 con una excepción ${ }^{19}$. Ahora bien, el ingreso de estos magistrados ${ }^{20}$ trajo consigo una polarización desde el punto de vista conceptual, pues cada subsección estaría integrada por magistrados antiguos y nuevos consejeros que tenían posturas diferentes ${ }^{21}$, especialmente en lo concerniente al nexo de causalidad.

18 Se habla de no aceptación plena, pues en ocasiones la Sección Tercera admite figuras propias de la imputación objetiva, como el principio de confianza. Sin embargo, la mención de dicho criterio fue tan escueta, que termina fusionándose con los criterios tradicionales de la causalidad, resultando difícil diferenciar los unos de los otros.

19 A la Sección Tercera del Consejo de Estado ingresaron los siguientes abogados: Jaime Alberto Santofimio Gamboa, Olga Valle de la Hoz, Hernán Andrade Rincón, Stella Conto Díaz del Castillo y Danilo Alfonso Rojas Betancourth. Estos profesionales se posesionaron en el mes de septiembre de 2010. La excepción fue la consejera Gladys Agudelo Ordóñez quien se desempeñaba en provisionalidad desde el mes de mayo de 2010, para sustituir la vacancia dejada por la consejera Myriam Guerrero de Escobar. Dicha vacancia fue suplida plenamente con el nombramiento como consejero del abogado Carlos Alberto Zambrano Barrera, el cinco de septiembre de 2011.

20 Teniendo en cuenta que los consejeros de Estado requieren para su nombramiento los mismos requisitos que un magistrado de la Corte Suprema de Justicia, el Consejo Superior de la Judicatura y la Corte Constitucional, es frecuente denominarlos magistrados. Por ello, en el presente documento se emplean los términos consejero y magistrado como sinónimos.

21 La Sección Tercera del Consejo de Estado, Sala de lo Contencioso quedó integrada (dentro del periodo de estudio) de la siguiente manera:

Subsección A

Hernán Andrade Rincón (nuevo)

Mauricio Fajardo Gómez (antiguo)

Gladys Agudelo Ordóñez (antigua) 
No obstante, la polarización conceptual no se encontraría en este detalle, sino en el hecho de que cada subsección conocería los mismos temas que las demás, pero con enfoques diferentes. Prueba de ello es la subsección B que de manera plena adoptó los criterios de la imputación objetiva para declarar patrimonialmente responsable al Estado, especialmente por falla en el servicio médico. Por el contrario, las otras subsecciones seguían empleando los criterios tradicionales para declarar patrimonialmente responsable a la Administración, especialmente el que hace relación al nexo de causalidad. A continuación se referencian algunos fallos de las distintas subsecciones de la Sección Tercera que permiten corroborar la anterior afirmación.

La subsección A, a inicios del año 2011, emitió un fallo en el cual se observa la gran dificultad que tiene para seguir sosteniendo la existencia de un nexo de causalidad y, por ende, la necesidad de probarlo. Sin embargo, en esta ocasión se recurrió a la teoría de la probabilidad preponderante, concepto teórico que permite aplicar la causalidad adecuada, admitiendo de esta forma justificar la no necesidad de certeza en la demostración del nexo causal, inclusive, el fallo en mención reconoce la dificultad que hay para

Subsección B

Ruth Stella Correa Palacio (antigua)

Stella Conto Díaz del Castillo (nueva)

Danilo Alfonso Rojas Betancourth (nuevo)

Subsección C

Enrique Gil Botero (antiguo)

Olga Valle de la Hoz (nueva)

Jaime Alberto Santofimio Gamboa (nuevo) demostrar la causa real que ocasionó el daño. Sin embargo, basta imputar el daño a la causa que tenga mayor preponderancia probabilística. Al respecto, la citada providencia judicial dijo lo siguiente (Consejo de Estado, 2011) ${ }^{22}$ :

$[\ldots]$

Todo lo dicho no quiere significar, en manera alguna, que la Sala desconozca que la exigencia probatoria respecto de la relación de causalidad, en no pocos eventos, difícilmente podrá comportar el acceso a niveles de certeza absoluta o de plena prueba, como quiera que se admite sin titubeos que si bien en principio del ligamen causal existente entre un hecho y un resultado puede predicarse su carácter de inmutable en cuanto dicha relación pende de las leyes de la naturaleza, mal podría desconocerse que la fe del pensamiento de la llustración en los avances científicos, en el paradigma mecanicista newtoniano y en el conocimiento empírico como herramientas aptas para proporcionar certezas incuestionables -al amparo de la idea de que el mundo natural está regido por leyes causales del tipo "si $\mathrm{X}$, entonces siempre $\mathrm{Y}^{\prime \prime}-$, dicha fe ha cedido el paso a la idea de que el conocimiento empírico no permite establecer con absoluta certeza si un hecho, como acontecimiento causal, es o no verdadero y que lo máximo que el saber científico posibilita es hallar el grado de probabilidad de la correspondiente cuestión fáctica con base en los elementos de juicio disponibles y en determinadas pautas de racionalidad.

\section{$[\ldots]$}

Actualmente no es aceptable ya un determinismo causal rígido, en virtud de la comprobación

22 Radicación número: 18793 
que la energía se libera en saltos discontinuos e irregulares cuyo origen y dirección no son aún conocidos.

\section{$[\ldots]$}

El riguroso mecanicismo es remplazado por el concepto de probabilidad como medida del azar: junto al mundo de la causalidad está también lo fortuito, la física cuántica ha combinado las ideas de causación y azar; lo que anteriormente se consideraban leyes comprobadas ahora se reputan verdades aproximadas, simples posibilidades, lo que conduce a un concepto flexibilizado de causa (énfasis en el texto original). GOLDENGERG, Isidoro, La relación de causalidad en la responsabilidad civil, cit., p. 7.

$[\ldots]$

\section{Acerca de la causalidad bajo el régimen de} responsabilidad extracontractual del Estado por la prestación de servicios de salud.

Esta Corporación nunca ha dejado de reconocer la dificultad que los demandantes enfrentan al asumir el deber de probar la relación de causalidad:

$[\ldots]$

No obstante, a propósito de la responsabilidad médica, debe quedar claro que los alivios dispuestos en ese régimen para la carga probatoria de la falla en el servicio no pueden también operar en lo que tiene que ver con la prueba de la relación de causalidad.

Es decir, la relación de causalidad queda probada cuando los elementos de juicio suministrados conducen a un grado suficiente de probabilidad.
Siempre se ha dicho que para que pueda ser declarada la responsabilidad patrimonial se requiere tener certeza sobre la existencia del nexo causal. Aun cuando en lógica formal la idea de probabilidad parezca oponerse a la idea de certeza, resulta oportuno destacar que ello no es así en el derecho de daños, porque la causalidad de que se trata es la adecuada $y$, por lo mismo, la probable, de manera que si la probabilidad es alta, lleva a la certeza acerca del nexo causal $y$, por consiguiente, abre paso a la condena, siempre que además haya prueba de la falla y del daño. Lo anterior, es el modo en que la llamada causalidad adecuada llega hasta sus más lejanas fronteras, en todo caso, sin invadir el mundo de la especulación:

“Ni aún en el evento de que se hubiera probado una falla del servicio habría lugar a declarar la responsabilidad del Estado mientras el vínculo causal no hubiera sido establecido, al menos como probable".

\section{$[\ldots]$}

Ahora bien, la diferencia entre "presunción de causalidad" -que no se aplica en estos casos- y "regla de prueba" -que sí se aplica-, no resulta inane toda vez que la primera, como presunción que es, puede ser desvirtuada por la parte contra la cual pesa, mientras que bajo la noción de regla de prueba se tiene que una vez verificado "el suficiente grado de probabilidad", queda establecido y plenamente probado el nexo causal.

Sin embargo, en fallo posterior -emitido por el mismo consejero (Consejo de Estado, 2011) ${ }^{23}$ se retorna a los criterios tradicionales para de-

23 Radicación número: 19192 
clarar patrimonialmente responsable al Estado (una conducta activa u omisiva imputable a la Administración, un daño y la relación de causalidad), pero recurriendo a la prueba indiciaria (y no a la teoría de las probabilidades) para demostrar la existencia del nexo causal. En efecto, después de hacer una mención de las diferentes teorías empleadas por el Consejo de Estado para probar la responsabilidad de la Administración, considera el ponente que la más apropiada, para el caso en estudio, es el empleo de la prueba indiciaria:

\section{$[\ldots]$}

2.- Régimen jurídico aplicable a los supuestos en los cuales se reclama el reconocimiento de responsabilidad extracontractual del Estado, ocasionada por los daños causados por razón de las actividades médico-asistenciales.

$[\ldots]$

Ahora bien, no pueden perderse de vista las dificultades que caracterizan la actividad probatoria en procesos como el que mediante el presente pronunciamiento se decide, habida cuenta de que la actividad médica entraña conocimientos técnicos y científicos de difícil constatación que, en determinados supuestos, le impiden al juez tener plena certeza sobre el nexo de causalidad existente entre un específico procedimiento médico y el resultado que al mismo se le pretende imputar. No obstante, la dificultad que conlleva el análisis de las pruebas en materia médica no faculta al juez para presumir la existencia del aludido nexo causal.

$[\ldots]$

Bien se observa entonces que el hecho conocido, o sea aquel a partir del cual se va a realizar la inferencia, debe estar cabalmente probado dentro del proceso por cualquier medio de prueba admisible, requisito central para que a partir del mismo el juez pueda arribar al hecho desconocido.

En consonancia con lo anterior, esta Corporación estimó procedente que los sujetos procesales, en juicios en los cuales se discute la responsabilidad extracontractual del Estado por razón del despliegue de actividades médicas, procuren la demostración de la existencia del nexo causal entre éstas y el daño irrogado a los demandantes a través de la prueba indiciaria... (Negrillas fuera del texto).

Desde una óptica diferente, la subsección $\mathrm{C}$ de la Sección Tercera del Consejo de Estado considera que los elementos para declarar patrimonialmente responsable al Estado son solo dos: la imputación y el daño. Este criterio, que venía siendo desarrollado por el consejero Enrique Gil Botero, es el que orienta la jurisprudencia de esta subsección (por lo menos hasta el momento).

En lo que se refiere a la imputación, la subsección B acoge los criterios desarrollados por la teoría de la imputación objetiva, estableciendo que habrá responsabilidad del Estado cuando este incumpla cualquiera de estas situaciones: a) el riesgo permitido, b) el principio de confianza, c) la posición de garante, d) la acción a propio riesgo, e) la prohibición de regreso, y f) el fin de protección de la norma. Si bien es cierto estos criterios hasta el momento no han sido desarrollados a cabalidad, es posible dilucidar su aplicación a partir de los fallos emitidos hasta el momento. Sin embargo, es importante mencionar que para el objeto de esta investigación, los 
fallos emitidos por la subsección C en materia de responsabilidad médica son reducidos, pero ello no significa que los criterios de la teoría de la imputación objetiva no se hayan aplicado en otros títulos de imputación ${ }^{24}$. Por esa razón, se expondrán los fallos emitidos por la recién creada subsección $B$ y que hacen relación a la demostración de una imputación y un daño para declarar civilmente responsable a la Administración.

El primer fallo condena al Estado en aplicación del criterio denominado res ipsa loquitur ${ }^{25}$, es decir, las cosas hablan por sí solas. En efecto, la subsección al desear aligerar la carga probatoria del demandante, consideró que la entidad demandada tenía responsabilidad al haber dejado en la humanidad de la víctima un cuerpo extraño que solo pudo haber llegado por una intervención quirúrgica previa y realizada por la demandada; en consecuencia, la decisión implica un primer derrotero en relación con lo expuesto por el Consejo de Estado en sentencias anteriores, toda vez que no se preocupó por demostrar el nexo causal, sino que de las pruebas se podía concluir una falla en el servi-

24 La subsección $\mathrm{C}$ de la Sección Tercera del Consejo de Estado ha aplicado los conceptos de la imputación objetiva en casos de privación injusta de la libertad y errores de la fuerza pública que han ocasionado el deceso a administrados.

25

De acuerdo con el Consejo de Estado:

"El concepto res ipsa loquitur o la cosa que habla por sí misma, es el nombre dado a una forma de evidencia circunstancial que crea una deducción de negligencia. Procede de los ordenamientos de common law donde cada día tiene mayor aceptación; el demandante solo tiene que probar el daño anormal o excepcional sufrido y la imputación del mismo a una entidad de derecho público; en su esencia indica que los daños producidos no se verifican normalmente si no existe una culpa, el hecho habla por sí como prueba de la culpa. A modo de ejemplo, no será necesario demostrar la negligencia del médico o del hospital en el que amputaron al enfermo la pierna equivocada o le extirparon un órgano distinto al que debían, o en el que murió un niño como consecuencia de una operación corriente". (Consejo de Estado, 2009). cio (imputación jurídica) que ocasionó un daño antijurídico a la víctima. Al respecto, la sentencia menciona lo siguiente (Consejo de Estado, 2011) $)^{26}$ :

\section{$[\ldots]$}

En efecto, si el daño deprecado consiste en el hecho mismo de que se haya verificado la existencia de un cuerpo extraño en el organismo del paciente, sin que se presenten daños o perjuicios adicionales, la responsabilidad estará regida por el concepto de falla del servicio probada a partir de la máxima res ipsa loquitur, lo que generará un acercamiento o aligeramiento probatorio entre el daño y la imputación. A contrario sensu, si en la demanda se solicitan o reclaman daños irrogados por la cosa misma, en virtud de la peligrosidad que le es intrínseca, y que han desencadenado patologías como por ejemplo infecciones, gangrenas, obstrucciones, etc., la responsabilidad de la administración sanitaria bajo estas hipótesis estará presidida por un régimen objetivo en el que no es posible eximirse o exonerarse de responsabilidad con la acreditación del comportamiento diligente y cuidadoso.

$[\ldots]$

En consecuencia, radicar en cabeza del demandante el deber de acreditar esos elementos constitutivos de la falla del servicio es inadmisible porque sería imponerle una carga en extremo difícil para la demostración de ese elemento de la responsabilidad, razón por la que, con base en criterios de equidad y justicia, se ha empleado el citado criterio de aligeramiento probatorio de la culpa basado en la contun- 
dencia de los hechos que constituyen el daño antijurídico.

En providencia posterior, la subsección $B$, por vez primera expresa de manera clara la importancia de aplicar los conceptos de la imputación objetiva para declarar la responsabilidad patrimonial de la Administración. En efecto, el ponente del fallo, hace mención exhaustiva de la teoría en mención, llegando al punto de expresar los conceptos con ella relacionados, lo que hasta el momento no había ocurrido. Otro aspecto importante en el fallo es que la subsección $\mathrm{C}$ considera que es la imputación objetiva la teoría que más se adecúa a los presupuestos del Estado social de derecho. Sobre estas consideraciones, el Consejo de Estado (2011) sostiene ${ }^{27}$ :

$[\ldots]$

Según lo prescrito en el artículo 90 de la Constitución, la responsabilidad extracontractual del Estado tiene como fundamento la determinación de un daño antijurídico causado a un administrado, y la imputación del mismo a la administración pública tanto por la acción, como por la omisión. Dicha imputación exige analizar dos esferas: a) el ámbito fáctico, y; b) la imputación jurídica, en la que se debe determinar: i) atribución conforme a un deber jurídico (que opera conforme a los distintos títulos de imputación consolidados en el precedente de la Sala: falla o falta en la prestación del servicio - simple, presunta y probada-; daño especial -desequilibrio de las cargas públicas, daño anormal-; riesgo excepcional); adicionalmente a lo anterior, resulta relevante tener en cuenta los aspectos de la teoría de la imputación objetiva de la responsabilidad patrimonial del Estado.

Sin duda, en la actualidad todo régimen de responsabilidad patrimonial del Estado exige la afirmación del principio de imputabilidad, según el cual, la indemnización del daño antijurídico cabe achacarla al Estado cuando haya el sustento fáctico y la atribución jurídica.

Debe quedar claro, que el derecho no puede apartarse de las "estructuras reales si quiere tener alguna eficacia sobre las mismas".

En cuanto a esto, cabe precisar que la tendencia de la responsabilidad del Estado en la actualidad está marcada por la imputación objetiva, título autónomo que "parte de los límites de lo previsible por una persona prudente a la hora de adoptar las decisiones".

$[\ldots]$

Siendo esto así, la imputación objetiva implica la "atribución", lo que denota en lenguaje filosófico-jurídico una prescripción, más que una descripción. Luego, la contribución que nos ofrece la imputación objetiva, cuando hay lugar a su aplicación, es la de rechazar la simple averiguación descriptiva, instrumental y empírica de "cuando un resultado lesivo es verdaderamente obra del autor de una determinada conducta".

Esto, sin duda, es un aporte que se representa en lo considerado por Larenz, según el cual había necesidad de "excluir del concepto de acción sus efectos imprevisibles, por entender que éstos no pueden considerarse obra del autor de la acción, sino obra del azar". Con lo anterior, se logra superar, definitivamente, en el juicio de responsabilidad, la aplicación tanto de la teoría de la equivalencia de condiciones, 
como de la causalidad adecuada, ofreciéndose como un correctivo de la causalidad, donde será determinante la magnitud del riesgo y su carácter permisible o no.

Dicha tendencia es la que marcó el precedente jurisprudencial constitucional, pero ampliando la consideración de la imputación (desde la perspectiva de la imputación objetiva) a la posición de garante donde la exigencia del principio de proporcionalidad es necesario para considerar si cabía la adopción de medidas razonables para prevenir la producción del daño antijurídico, y así se motivara el juicio de imputación. (Negrillas fuera del texto).

La jurisprudencia elaborada por la subsección B goza de una fuerte carga conceptual de concepciones iusfilosóficas y más cercanas a la teoría constitucional que a las tradicionales del derecho administrativo. A su vez, se observa la forma como los magistrados encuentran en el derecho $-y$ no en un concepto naturalístico como lo es el nexo causal- los fundamentos teóricos para imputarle daños a la Administración.

\section{CONCLUSIONES}

A partir del año 1999 comenzaron a variar las teorías empleadas por la Sección Tercera del Consejo de Estado en relación con el nexo causal, pasando de la falla presunta (que regía desde el año de 1992) a la probabilidad preponderante, para luego aplicar en el año 2000 la teoría de la carga dinámica de la prueba (fundamentándose en el artículo 117 del Código de Procedimiento civil). A su vez, en este mismo periodo existió el uso fundamentado de la teoría ecléctica, como es el asumir la falla probada como regla general y permitir en casos especiales la carga dinámica de la prueba o algún aligeramiento probatorio, lo que demuestra la incertidumbre conceptual del Consejo de Estado para tratar de fundamentar la existencia del nexo causal como elemento necesario para declarar la responsabilidad del Estado.

Otro de los elementos conceptuales a los cuales tuvo que recurrir la Sección Tercera del Consejo de Estado fue el indicio. En efecto, desde el año de 1999 se fue generando un movimiento alrededor del indicio, consistente en verlo como un aligeramiento probatorio que se puede confrontar con la probabilidad preponderante. Esta última teoría tuvo especial relevancia a partir del año 2006 y es una de las concepciones que acogió la Sección Tercera, subsección A del Consejo de Estado, para fundamentar sus fallos en los asuntos de responsabilidad médica estatal.

A partir del año 2007, con la entrada del consejero Enrique Gil Botero, se empieza a perfilar una nueva concepción jurisprudencial en lo que hace referencia a la relación de causalidad (denominada por él imputación fáctica para diferenciarla de la imputación jurídica o verdadera imputación). Este consejero plantea en sus múltiples salvamentos de voto que los componentes de la responsabilidad patrimonial del Estado son predominantemente valorativos o normativos, prescindiendo del concepto de relación de causalidad. Sin embargo, estas posiciones conceptuales no tuvieron la fuerza suficiente para modificar la postura tradicional de defender la existencia del nexo de causalidad en la responsabilidad del Estado por falla médica. Sin embargo, a partir del último trimestre del año 
2010, con la entrada en operación de las subsecciones de la Sección Tercera del Consejo de Estado, empieza a darse un giro total a la escogencia de la teoría de la imputación objetiva para imputarle daños antijurídicos a la nación. Esta postura conceptual solo fue acogida por la subsección C, pues las demás (con excepción de la subsección B que aún no se ha pronunciado sobre este título de imputación $\left.{ }^{28}\right)$, siguen aplicando las teorías "tradicionales" sobre el nexo de causalidad (especialmente la de la probabilidad preponderante).

Lo anterior trae como consecuencia una clara inseguridad jurídica, pues no es posible establecer a ciencia cierta qué criterios emplea la Sección Tercera del Consejo de Estado. En otras palabras, la teoría a aplicar dependerá de la subsección que conozca el problema jurídico a resolver, lo cual traerá como consecuencia, la dificultad de aplicar el precedente judicial tal y como lo plantea el ordenamiento jurídico colombiano actual, por lo que resultaría necesario expedir una sentencia de unificación por parte de la Sala Plena del Consejo de Estado, Sala de lo Contencioso Administrativo, para generar seguridad jurídica en relación con este concepto ${ }^{29}$.

Si bien no es posible inferir de las sentencias las razones por las cuales se presentaron los cambios jurisprudenciales ${ }^{30}$, sí es posible afir-

28 Dentro del marco de delimitación de esta investigación, hasta septiembre de 2011, no existía pronunciamiento alguno por parte de esta subsección en relación con la responsabilidad médica del Estado.

29 Artículo 10 de la Ley 1437 de 2011 o Código de Procedimiento Administrativo y de lo Contencioso Administrativo.

30 Se buscó acceder a las actas de deliberación de la Sección Tercera (antes y después de la creación y entrada en funcionamiento de mar que ello se debió al ingreso de nuevos consejeros de Estado que venían con planteamientos doctrinales diferentes en relación al nexo de causalidad. A su vez, es posible intuir que al facilitar o dificultar la carga probatoria sobre el nexo causal se incrementaría o disminuiría el número de demandas contenciosas contra el Estado, lo que podría ser una razón para modificar las teorías sobre la relación de causalidad.

Para finalizar, de los hechos que fundamentan las sentencias se puede inferir lo tardía que es la jurisdicción de lo contencioso administrativo. En efecto, muchos de los casos fueron fallados casi quince (15) años después de la ocurrencia de los hechos. Este fue uno de los fundamentos que llevó a la expedición de la Ley 1285 de 2009 que creó, entre otras varias instituciones, las tres subsecciones que integrarían la Sección Tercera del Consejo de Estado.

\section{Bibliografía}

CoIng, Helmut, (1982), Historia del Derecho y Dogmática Jurídica, Revista Chilena de Derecho, volumen 9.

Consejo de Estado, Sala de lo Contencioso Administrativo, Sección Tercera, sentencia del veinte y seis (26) de abril de novecientos noventa y nueve (1999), radicación número 10755, consejero ponente: Ricardo Hoyos Duque. 
Consejo de Estado, Sala de lo Contencioso Administrativo, Sección Tercera, sentencia de tres (3) de mayo de mil novecientos noventa y nueve (1999), radicación número: 11169, consejero ponente: Ricardo Hoyos Duque.

Consejo de Estado, Sala de lo Contencioso Administrativo, Sección Tercera, sentencia de diez (10) de febrero de dos mil (2000), radicación número: 11878, consejero ponente: Alier Eduardo Hernández Enríquez.

Consejo de Estado, Sala de lo Contencioso Administrativo, Sección Tercera, sentencia de quince (15) de junio de dos mil (2000), radicación número: 12548, consejera ponente: María Elena Giraldo Gómez.

Consejo de Estado, Sala de lo Contencioso Administrativo, Sección Tercera, sentencia del catorce (14) de junio de dos mil uno (2001), radicación número: 11901, consejero ponente: Alier Eduardo Hernández Enríquez.

Consejo de Estado, Sala de lo Contencioso Administrativo, Sección Tercera, sentencia del quince (15) de agosto de 2002, radicación número: 11605, consejero ponente: Alier Hernández Enríquez.

Consejo de Estado, Sala de lo Contencioso Administrativo, Sección Tercera, sentencia de primero (1) de julio de dos mil cuatro (2004), radicación número: 14696, consejero ponente: Alier Eduardo Hernández Enríquez.

Consejo de Estado, Sala de lo Contencioso Administrativo, Sección Tercera, sentencia de veinte (20) de abril de dos mil cinco (2005), ra- dicación número: 14699, consejero ponente: Ramiro Saavedra Becerra.

Consejo de Estado, Sala de lo Contencioso Administrativo, Sección Tercera, sentencia de diecinueve (19) de septiembre de dos mil siete (2007), radicación número: 15382, consejero ponente: Enrique Gil Botero.

Consejo de Estado, Sala de lo Contencioso Administrativo, Sección Tercera, sentencia de diecinueve (19) de septiembre de dos mil siete (2007), radicación número: 16010, consejero ponente: Enrique Gil Botero.

Consejo de Estado, Sala de lo Contencioso Administrativo, Sección Tercera, sentencia del cuatro (04) de junio de dos mil ocho (2008), radicación número: 16646, consejero ponente: Ramiro Saavedra Becerra.

Consejo de Estado, Sala de lo Contencioso Administrativo, Sección Tercera, sentencia de primero (1) de octubre de dos mil ocho (2008), radicación número: 27268 , consejero ponente: Enrique Gil Botero.

Consejo de Estado, Sala de lo Contencioso Administrativo, Sección Tercera, sentencia de diecinueve (19) de agosto de dos mil nueve (2009), consejero ponente: Enrique Gil Botero.

Consejo de Estado, Sala de lo Contencioso Administrativo, Sección Tercera, Subsección A, sentencia de febrero nueve (09) de dos mil once (2011), radicación número: 18793, consejero ponente: Mauricio Fajardo Gómez. 
Consejo de Estado, Sala de lo Contencioso Administrativo, Sección Tercera, subsección C, sentencia de veinticuatro (24) de marzo de dos mil once (2011), radicación número: 20836, consejero ponente: Enrique Gil Botero.

Consejo de Estado, Sala de lo Contencioso Administrativo, Sección Tercera, subsección C, sentencia de trece (13) de abril de dos mil once (2011), radicación: 20220, consejero ponente: Jaime Orlando Santofimio Gamboa.

Consejo de Estado, Sala de lo Contencioso Administrativo, Sección Tercera, Subsección A, sentencia de abril veintisiete (27) de dos mil once (2011), radicación número: 19192, consejero ponente: Mauricio Fajardo Gómez.

Corte Constitucional, Sentencia C-333 de primero

(1) de agosto de 1996, magistrado ponente: Alejandro Martínez Caballero.
GIL Botero, Enrique, (2011), Responsabilidad extracontractual del Estado, Temis, Bogotá D.C.

Leiva Ramírez, Eric, (2009), La inoperante aplicación del nexo de causalidad en la responsabilidad civil del Estado, Administración \& Desarrollo, Escuela Superior de Administración Pública, No. 37 (51).

López Medina, Diego, (2006), El derecho de los jueces, Legis, Bogotá D.C.

Rodríguez Rodríguez, Libardo, (2008), Derecho administrativo general y colombiano, Temis, Bogotá D.C.

Ruíz Orejuela, Wilson, (2010), Responsabilidad del Estado y sus regímenes, Ecoe ediciones, Bogotá D.C. 